\title{
Editorial:
}

\section{Celebrating the Multiplicity of Social Work}

An Invitation to a Translation Practice

by

Yan Zhao

Associate Professor, PhD

University of Nordland

Email: Yan.zhao@uin.no 
I originally come from a country where there is little tradition in social work, both as a discipline and as a profession. For a long time, the Chinese communist regime had believed that the emergence and development of social work is a particular characteristic of Western capitalism for the purpose of solving various inevitable social problems caused by the capitalist market economy. It was not until the end of 1980s and early 1990s that the Chinese government began to see the need for the development of social work, which led to the establishment of the education programme in universities (see Leung et al., 2012). Today, when telling my Chinese friends that I teach social work in Norway, I am still encountered with this frequently asked question, "What is social work, and what does a social worker do?"

I can certainly pick up some ready-made definitions from the books that I use in my teaching and research. However, when you have to explain these definitions within a different social, structural and cultural context, and in a language that strictly limits you to this context, the definitions seem to have lost their meaning. You are then often further asked, "Oh, what does that mean?" You are expected to explain it in relation to the social realities (here and now) and cultural schemes that your audience is used to, which is not an easy task. Challenges lie in what Judith Butler deploys as "cultural intelligibility" (Butler, 1993). To translate knowledge, not only linguistically but also culturally, from one social context to another is therefore challenging. In my attempt to explain what social work is and what a social worker does (indeed a knowledge translation process) to my Chinese friends, I see that categories I use are inscribed with different meanings. Though this is not surprising to me, who is in fact familiar with the Chinese "cultural intelligibility", each time I feel amazed to see how my explanation of social work can turn it into something new or something other than what I have been used to in a Norwegian context. Borrowing a concept from Actor-Network-Theory, which is interested in studying such processes of translation (see Callon, 1986"ii), we can say that social work in a global context is a multiple enactmentiil - it is enacted to different practices and different theorizations under various cultural contexts and various welfare and political regimes.

Nonetheless, the multiplicity of social work does not only concern a question of a social and cultural context. As a professional practice, social work deals with multiple 
problems and issues, from the classical social problem of poverty, to more traditional issues related to child protection, elder care, domestic violence, homelessness, disability, mental illness, and to the increasingly more and more commonplace lifestyle problems such as drug addiction, gambling, eating disorders, self-injury and so on. When a social worker is working with concrete cases, she or he can easily find out how these multiple problems can be intertwined and circled together. To help service users solve the problems, we cannot think about the problems separately.

Closely related to the multiplicity of work issues within the profession, as a discipline and research field, social work is interdisciplinary and built upon multiple disciplines such as sociology, psychology, political science, pedagogy, law, philosophy and ethnics. At the same time, it incorporates knowledge from other interdisciplinary research fields such as gender and women's studies, ethnic and racial studies, migration studies and adoption studies.

As an international journal of social work that has a focus on the comparative aspect in the knowledge production in this research field, we welcome and try to grasp this multiplicity when presenting the new findings of this knowledge field. A comparative perspective does not simply mean putting two or more things together for showing the similarities and differences. It requires us to make links in analysis by transgressing borders that can be geographical, social, cultural, thematic or disciplinary. This is indeed a process of doing translations, so that the different contexts, themes and disciplines can talk to each other. In other words, doing comparative studies means "establishing a meaningful dialogue between ideas and evidences" (Ragin, 1987, p. viii). This issue of the Journal of Comparative Social Work mirrors the multiplicity of the social work research. It includes three peerreviewed articles, one philosophical essay and two student essays. All of them can all be said to have conducted such a border crossing translation practice, though some are more explicit than others. Some can be said to be cultural and social contextual translations and some thematic, while others are theoretical.

Carina Fjelldal-Soelberg's article takes up the issue of self-harm among young women in Norway, a topic that has attracted more and more attention not only from 
the media, but also from social workers who have worked with these youths. Based on 12 in-depth interviews she had with women who injured their bodies, FjelldalSoelberg discusses how a cultural discourse on the normativity of gender has influenced these women's experience of having an injured body. Adopting a poststructuralist approach on gender understood as an embodied performance of certain socially constructed femininities/masculinities, her analysis illustrates well how for those young women she interviewed, doing bodily self-injury is simultaneously a process of doing gender in relation to a series of established norm on what Judith Butler calls "girling" (Butler, 1993). If an injured or defective female body is a cultural deviation that requires an intervention from social work, FjelldalSoelberg's analysis points out the significance of gender, and demonstrates how the cultural norm on gender, or more concretely, the Western ideal on femininity, has contributed to the social construction of the deviation.

The problem of homelessness has increased in a global scope. In a Western context, this problem is often intertwined with drug addiction, economic and mental problems. How can social workers intervene to help solve or prevent the problem? Rita Elisabeth Eriksen's article takes up this issue, and addresses how a task-centred coping approach (TCCA) in a Norwegian context can contribute to enhance the housing competence of those who face housing challenges. Based on a study of an educational and developmental programme with both practitioners and service users in which TCCA is applied, Eriksen has chosen to focus on the service users' experience of exploring the potential of the TCCA - that is, how did they evaluate their own everyday life situation and housing competence after fulfilling the programme, and how did they experience the inclusion of TCCA in their efforts to better their life situations? The author concludes that the TCCA has generally had a positive effect on evolving the service users' housing competence, with the potential of this approach mainly lying in an orientation towards coping and user participation, both of which, according to Eriksen's analysis, can contribute to an increasing awareness among the service users of their resources and own strength.

The last article, written by Vibeke Samsonsen and Elisabeth Willumsen, is based on a comparative study of the social workers' experiences with two assessment models 
in Child Protection Services: the "professional judgement model", and the "structured assessment model", which are applied in Norway and England, respectively. The comparison is conducted around three central themes: the assessment structure, professional judgement, and social contexts such as public debates with the involvement of the media and institutional resources. The two authors have also discussed their findings in light of the concept of "accountability" to help shed light on how governmental trust and a need for public control can influence the design and choice of Child Protection assessment models in different contexts. Furthermore, in this article the authors also ask: What we can learn from the comparisons? The ongoing debates and critical evaluations of the assessment models in the two contexts seem to imply that the Norwegian model needs to be more structured and standardized, while the English model requires a bigger amount of room for social workers' professional judgement (e.g. Munro, 2011; Report of Auditor General of Norway, 2012). However, the authors argue that the critiques cannot be simply understood as a call for a paradigm shift in both countries. Certain contextual and institutional factors, such as different models of welfare regimes in Child Protection, media culture and public opinions have pre-shaped the assessment practice in the two respective countries.

Ethics is always an important issue in all professions that work with people. Even so, how can the ethics of a specific philosopher be of relevance to social work? In this issue of the JCSW, we have included a philosophical essay that endeavours to "translate" the relevance of the Danish philosopher, Knud Ejler Løgstrup's relational ethics to the practice fields of social work, health care, psychotherapy and pedagogical practices. As a practice-oriented philosopher, author Anders Lindseth focuses on the philosophy and ethics' application values to concrete professional practices. For example, at the beginning of the article, he introduces the theme of the essay by presenting an ethical dilemma a psychiatrist experienced when working with a long-term patient who refused to wash herself - a dilemma many social workers (at least in a Nordic context) can easily recognize in their own professional practice. Exactly because of his focus on practice, Lindseth turns an abstract philosophical discussion into an interesting philosophical exploration on how we can 
do justice to the life of the Other as it is laid in our hands and how we can meet people in need of our help in an ethical way.

Publishing good student essays has been a tradition for the JCSW. For us editors, these essays are interesting personal explorations of making links between theoretical knowledge and practice situations in their own social, cultural and thematic contexts. The reflective aspect in the essay concerns a question of personally situating in applying as well as producing knowledge in/through practices. We consider this practice of making links and situating to be both necessary for the students to evolve their professional competence, and important for us academics to help enrich our contextual understanding in our own knowledge productions. In this issue, we have chosen two student essays. As a foreign part-time social worker working with social care in Norway, Natalie Shavrina reflects on her experience of working with a service user with Asperger syndrome, who like herself, also has a foreign background. In this essay, Shavrina explores the different aspects of power relations between the service user and herself, as well as between the service user and other more experienced social workers. In her reflection, she points out that a rigid understanding and division of privileged vs. underprivileged power positions can become problematic in a concrete practice situation. By challenging the dualistic understanding of power relations, she provides an alternative understanding of how to perceive her relations with the service user. Based on this new understanding, she has also enhanced her understanding of what self-determination can mean in a particular practice situation. In the second essay, Memory J. Tembo revisits her encounter with a disabled woman in Rural Malawi. Although Tembo met this woman as a researcher assistant, the specific social settings of this meeting and the actual positioning between the two parts make it possible for her to situate herself as a social worker in her exploration of knowledge when revisiting this experience. Tembo's point of departure in her reflection was that she was helpless when attempting to help the disabled woman out of a difficult life situation. She therefore raises a question: If she was a social worker, how she could possibly handle the situation in a better way? To help answer this question, she first applies the system theory to deepen her understanding of the problems that the disabled woman faced in a Malawian context, which is followed by her discussion on what can be possible 
intervening practices based on Western theories on empowerment and a strength perspective.

As the editor of this issue, I hope that the above introduced articles and essays can be of relevance and use to your own social work practice and/or research. As I have expounded, knowledge production in social work is a multiple enactment that requires a constant practice of translation. In this way, I invite you to further the translation process as started in these articles and essays in your own reading so that the findings, knowledge and perspectives can find new lives or new enacted values in your own context - and not only in the social and cultural context where you are geographically situated, but also in the thematic and theoretical contexts where your work is situated. Enjoy your reading!

\footnotetext{
'Butler refers "Cultural intelligibility" to the production of a normative framework that conditions who can be recognized as a legitimate subject (Butler, 1993). Here, I borrow this concept to show that the same normative framework also conditions our understanding of what is legitimate knowledge. ii Though Callon's focus is primarily on how knowledge (say concepts and theories) is translated between different knowledge fields.

iii In Science and Technology Studies (STS), the concept of "enactment" is applied to show how different realities have been enacted or constructed in knowledge production and how interdisciplinary knowledge can change over time, while both conserving forms of authority and shifting the terms of authority (see Mol, 2002; King, 2011).
} 


\section{References}

Butler, J. (1993). Bodies that matter: On the discursive limits of "sex". New York: Routledge.

Callon, M. (1986). "Some Elements of a Sociology of Translation: Domestication of the Scallops and the Fishermen of St Brieuc Bay." pp. 196-233. In J. Law (Ed.), Power, Action and Belief: A New Sociology of Knowledge. London: Routledge \& Kegan Paul.

King, K. (2011). Networked Reenactments: Stories Transdisciplinary Knowledges Tell. Durham: Duke University Press.

Leung, T. T. F., Yip, N. M., Huang, R., \& Wu, Y. (2012). "Governmentality and the Politicisation of Social Work in China" in British Journal of Social Work 42(6). Oxford: Oxford Journals.

Mol, A. (2002). The body multiple: Ontology in medical practice. Durham: Duke University Press.

Munro, E. (2011). The Munro Review of Child Protection: Final Report. A Child-Centred System. London: Department of Education.

Ragin, C. C. (1987). The comparative method: Moving beyond qualitative and quantitative strategies. Berkeley, Calif.: University of California Press.

Report of Auditor General of Norway (2012). Document 3:15 (2011-2012). Oslo: Fagbokforlaget. 